\title{
Calcium imaging reveals depressive- and manic-phase-specific brain neural activity patterns in a murine model of bipolar disorder: a pilot study
}

\author{
Min Chen ${ }^{1,6 \times}$, Hongjun Tian ${ }^{2,6}$, Guoyong Huang ${ }^{3,4,5,6}$, Tao Fang ${ }^{2}$, Xiaodong Lin $^{3,4,5}$, Jianmin Shan ${ }^{3,4,5}$, Ziyao Cai ${ }^{3,4,5}$, \\ Gaungdong Chen ${ }^{3,4,5}$, Suling Chen ${ }^{3,4,5}$, Ce Chen ${ }^{3,4,5}$, Jing Ping ${ }^{3,4,5}$, Langlang Cheng ${ }^{3,4,5}$, Chunmian Chen ${ }^{3,4,5}$, Jingjing Zhu L $^{3,4,5}$, \\ Feifei Zhao ${ }^{3,4,5}$, Deguo Jiang ${ }^{3,4,5}$, Chuanxin Liu' ${ }^{1}$, Guangchuan Huang ${ }^{1}$, Chongguang Lin ${ }^{3,4,5 凶}$ and Chuanjun Zhuo (iD) ${ }^{1,2,3,4,5 凶 '}$
}

(c) The Author(s) 2021

Brain pathological features during manic/hypomanic and depressive episodes in the same patients with bipolar disorder (BPD) have not been described precisely. The study aimed to investigate depressive and manic-phase-specific brain neural activity patterns of BPD in the same murine model to provide information guiding investigation of the mechanism of phase switching and tailored prevention and treatment for patients with BPD. In vivo two-photon imaging was used to observe brain activity alterations in the depressive and manic phases in the same murine model of BPD. Two-photon imaging showed significantly reduced $\mathrm{Ca}^{2+}$ activity in temporal cortex pyramidal neurons in the depression phase in mice exposed to chronic unpredictable mild stress (CUMS), but not in the manic phase in mice exposed to CUMS and ketamine. Total integrated calcium values correlated significantly with immobility times. Brain $\mathrm{Ca}^{2+}$ hypoactivity was observed in the depression and manic phases in the same mice exposed to CUMS and ketamine relative to naïve controls. The novel object recognition preference ratio correlated negatively with the immobility time in the depression phase and the total distance traveled in the manic phase. With recognition of its limitations, this study revealed brain neural activity impairment indicating that intrinsic emotional network disturbance is a mechanism of BPD and that brain neural activity is associated with cognitive impairment in the depressive and manic phases of this disorder. These findings are consistent with those from macro-imaging studies of patients with BPD. The observed correlation of brain neural activity with the severity of depressive, but not manic, symptoms need to be investigated further.

Translational Psychiatry (2021)11:619; https://doi.org/10.1038/s41398-021-01750-8

\section{INTRODUCTION}

Bipolar disorder (BPD) is a chronic psychiatric disorder affecting $1-4 \%$ of the global population [1]. With advances in multiple research techniques, the pathological features of BPD have been increasingly examined from different perspectives [2-10]. Based mainly on magnetic resonance imaging (MRI) and electroencephalographic (EEG) findings, the macro-brain connectivity hypothesis holds that brain circuit connectivity disturbance in the emotion and reward networks in bipolar illness can guide larger-scale efforts to understand how the human brain architecture impacts mood regulation in patients with BPD [11-18]. Micro-brain connectivity evidence, provided mainly by molecular studies based on the brain development hypothesis and performed with animal models, suggests that homeostatic structural plasticity is disturbed in BPD [19-31]. Moreover, accumulating studies based on the monoamine theory suggest that the dopamine transporter, oxytocin, and dopamine systems act in tandem to regulate corticostriatal circuitry, and that this synergistic interaction is perturbed in patients with BPD [17-50]. Thus, the current evidence suggests that disturbances of macroand micro-brain connectivity and monoamine transmitters are the pathological features of BPD, and that these features are caused by neuronal axon, dendrite, brain transmitter, and brain electrical activity dysfunction, as well as genetics and epigenetics (reciprocal gene-environment interactions) [20-55]. More importantly, macro- and micro-brain connectivity is correlated due to the disturbance of neural synapse connections in BPD [32-50].

Few studies, however, have examined manic/hypomanic or depressive phase-specific pathological features of BPD [37, 38]. Moreover, dynamic alterations in brain functional activity, cognition, and behavior during the switching phase of BPD have rarely been examined in the same patient or animal model. Such research can provide important information about the mechanism underlying phase switching, ultimately guiding the targeting of

\footnotetext{
${ }^{1}$ Micro-imaging Center of Psychiatric Disorder, Institute of Mental Health, Jining Medical University, 272013 Jining, China. ${ }^{2}$ Key Laboratory of Real Time Imaging of Brian Circuits in Psychiatry and Neurology (RTIBNP_Lab), Tianjin Fourth Center Hospital Affiliated to Nankai University, Tianjin Fourth Center Hospital; Tianjin Mental Health Center of Tianjin Medical University, 30022 Tianjin, China. ${ }^{3}$ Center of Psychiatric Animal Model, Institute of Mental Health, Wenzhou Seventh Peoples Hospital, 325000 Wenzhou, China.

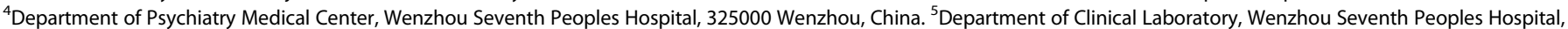
325000 Wenzhou, China. ${ }^{9}$ These authors contributed equally: Min Chen, Hongjun Tian, Guoyong Huang. ${ }^{凶}$ email: chmj@vip.163.com; Icg25@126.com; Chuanjunzhuotjmh@163.com
} 
treatment for patients with BPD and prevention high-risk individuals with family histories of the BPD [48-56]. In recent years, in vivo two-photon calcium imaging has been used to investigate brain pathological features in animal models of neocortical processing disorder and neurological and mental diseases [46-54]. In addition, brain alteration patterns have been found to differ among the stages of BPD progression [45-56].

Hence, in the present pilot study, we used in vivo two-photon imaging to observe brain activity alterations during the depressive and manic/hypomanic phases in a murine model of BPD. As clinical studies have shown that depressive episodes usually precede manic episodes in patients with BPD, we established the model with induction of the depressive phase by chronic unpredictable mild stress (CUMS) application [57], followed by manic-phase induction by ketamine injection [58-60]. We hypothesized that: (1) in vivo calcium imaging would demonstrate impaired neural activity in the temporal cortex (TPC) and prefrontal cortex (PFC), (2) this impairment would have phasespecific patterns, (3) these patterns would be associated with differences in cognitive and behavioral performance between BPD phases, and (4) the patterns would be related to macro- and micro-brain connectivity features.

\section{MATERIALS AND METHODS \\ Animals and experimental design}

Male C57BL/6 mice aged 4-5 weeks were housed in groups in a standard animal facility with free access to food and water. An adeno-associated viral (AAV) vector expressing GCaMP6s, a fluorescent calcium indicator, was injected stereotaxically into the TPC and PFC of each mouse. We investigated neural transmission in the TPC and PFC because these loci are the seats of higher emotional and cognitive function and have been implicated in the pathogeneses of depression and mania [47-71]. After recovering from this procedure, the mice were divided randomly into two groups: negative controls with no exposure or treatment and BPD mice. The investigators were blinded to the groups during experiments. The ethics committees of Wenzhou Seventh and Tianjin Fourth Center hospitals approved this study (IRB-2020-animal-BPD-001 and IRB-2020TJFCH-004, respectively), and all procedures were performed in accordance with the hospitals' ethical standards.

The BPD model was designed to mimic a protocol for mania prevention [55-60]. Following our previous work, we established it by exposing the mice to CUMS using a standard protocol to provoke depressive behavior; 1 day later, we initiated a course of daily intraperitoneal injection of ketamine $(25 \mathrm{mg} / \mathrm{kg})$ to provoke manic behavior [68-71]. Assessments were performed after the establishment of each phase.

\section{Stereotaxic injection}

Anesthesia was induced with $1.25 \%$ avertin, the scalp was incised and locally sterilized, and the periosteal tissue was removed. A stereotaxic instrument (RWD, China) was used to identify the hindlimb region of the primary somatosensory cortex ( $\mathrm{S} 1 \mathrm{HL}$; about $0.5 \mathrm{~mm}$ anterior to bregma and $1.5 \mathrm{~mm}$ lateral). An injection hole was created on the cranium with a high-speed microdrill (OmniDrill35; WPI, Jerusalem, IL, USA), and a glass microelectrode connected to an ultra-micro-injection pump (Nanoliter 2010; WPI) was used to inject $80 \mathrm{nl} \mathrm{AAV2/1-hSyn-GCaMP6s} \mathrm{or} 150 \mathrm{nl}$ AAV2/ 1-hSyn-DIO-GCaMP6s ( $>1 \times 10^{13}$ gene copies/ml; University of Pennsylvania Gene Therapy Program Vector Core) into the fifth cortical layer at a $60^{\circ}$ angle to avoid imaging site damage. The glass electrode was kept in the brain tissue for a total of $5 \mathrm{~min}[72,73]$.

\section{In vivo two-photon calcium imaging}

Three weeks after stereotaxic injection, the mice were anesthetized with $1.25 \%$ avertin, the skull was exposed, and two metal bars were attached to the rostral and caudal portions of the skull, respectively, with glue (Loctite 401) and dental cement to ensure head restraint during imaging. One day later, a high-speed microdrill was used to create an imaging window above $\mathrm{S} 1 \mathrm{HL}$. A glass coverslip was applied to the window using Vetbond tissue adhesive (3M, USA).

In vivo calcium imaging was performed on awake mice under head restraint using a 920-nm excitation laser with a water-immersed objective $(\times 20,1.1$ numerical aperture; Zeiss, Germany). Under an LSM780 twophoton microscope (Zeiss), calcium activity was recorded at $2 \mathrm{~Hz}$ for $2.5 \mathrm{~min}$ at the apical tufts $(0-80 \mu \mathrm{m}$ from pia), vasoactive intestinal polypeptide somas and axons (200-300 $\mu \mathrm{m}$ from pia), somatostatin somas and axons $(400-500 \mu \mathrm{m}$ from pia), and layer 5 pyramidal neuron somas (600-650 $\mu \mathrm{m}$ from pia). These regions of interest were defined manually. Calcium-signal time series were corrected using the TurboReg plugin for ImageJ software (National Institutes of Health, Bethesda, MD, USA). Mean pixel values were averaged to obtain fluorescent $(F)$ values, normalized as $\left(\Delta F-F_{0}\right) / F_{0}$, where $F_{0}$ (the baseline value) was the average obtained during the first $10 \%$ of recording. Total integrated calcium values were calculated by summing $\Delta F / F_{0}$ values for the entire time series. Calcium spikes were defined as $\geq 3$ standard deviation increases $[74,75]$.

\section{Behavioral assays}

The animals were subjected to a sucrose preference test as described previously [76-79], followed by a prepulse inhibition (PPI) test adapted for the quantification of sensory gating function [80, 81]. After acclimation of the mice in a sound-isolating chamber with $65 \mathrm{~dB}$ background noise, a 75$\mathrm{dB}$ prepulse (PP) was applied for $20 \mathrm{~ms}$, followed $100 \mathrm{~ms}$ later by a $40-\mathrm{ms}$ 120-dB startle stimulus (PA). The mice completed three trials with intervening intervals of $30 \mathrm{~s}$. Scores were averaged and the PPI ratio was calculated as (PA-PP)/PA $\times 100 \%[76-81]$.

\section{Statistical analysis}

Sample size was determined based on previous published data as sufficient to obtain statistical significance. No randomization was performed. Data are presented as means \pm standard errors of the mean, unless specified otherwise. Data were compared using one-way analysis of variance and post hoc Tukey tests. Data analysis and figure plotting were performed with the GraphPad Prism software (version 8.0) [65, 66]. No animals were excluded from the present study.

\section{RESULTS}

\section{CUMS and ketamine exposure evoked abnormal cortical} transmission and behavior

Compared with controls, mice exposed to CUMS and ketamine had significantly longer immobility times in the depression phase $(P<$ 0.001 ; Fig. 1c) and significantly greater total distances traveled in the manic phase $(P<0.001$; Fig. $2 \mathrm{c})$. Two-photon calcium imaging demonstrated significantly less $\mathrm{Ca}^{2+}$ activity in TPC pyramidal neurons in the depression phase, but no significant abnormality in the manic phase, in these mice (Figs. $1 \mathrm{a}, \mathrm{b}$ and $2 \mathrm{a}, \mathrm{b}$ ). Compared with the controls, $\mathrm{Ca}^{2+}$ hypoactivity was observed in the PFC in the depression and manic phases in mice exposed to CUMS and ketamine (Figs. 1e, $f$ and $2 \mathrm{e}, \mathrm{f}$ ). Total integrated calcium values correlated significantly with immobility times in the depression phase, but not the manic phase $(P<0.001$, Fig. $1 \mathrm{~d} ; P<0.001$, Fig. $2 \mathrm{~b})$, due primarily to decreased calcium spike frequencies $(P<$ 0.001 , Fig. $2 c, d)$. In both phases, exposed mice had smaller novel object recognition preference ratios than did controls $(P<0.001$; Figs. $1 \mathrm{~g}$ and $2 \mathrm{~g}$ ). This ratio correlated negatively with the immobility time in the depression phase and with the total distance traveled in the manic phase (Figs. $1 \mathrm{~h}$ and $2 \mathrm{~h}$ ). Thus, mice exposed to CUMS and ketamine showed dual phenotypes of depression and manic behavior largely consistent with the behavioral expression of patients with BPD, reflecting successful BPD model establishment. They exhibited impaired cognitive ability in the depressive and manic phases, which was more severe in the depressive phase.

\section{Relationships among brain $\mathrm{Ca}^{2+}$ activity, symptom severity,} and cognitive impairment

Brain $\mathrm{Ca}^{2+}$ activity was related negatively to the severity of depression (Fig. 1d). A similar, but nonsignificant, trend was observed for the severity of mania (Fig. 2d). The relationships between symptoms and cognitive impairment were consistent in the depressive and manic phases. Cognitive impairment was more severe and more strongly correlated with symptom severity in the manic phase than in the depressive phase. 
a

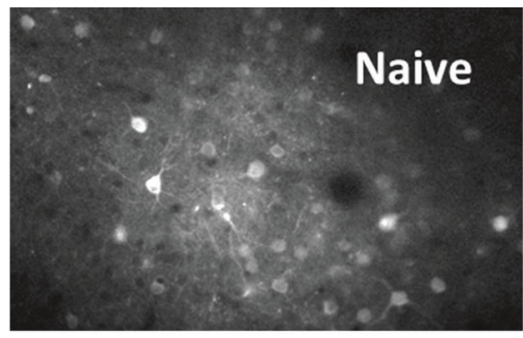

b

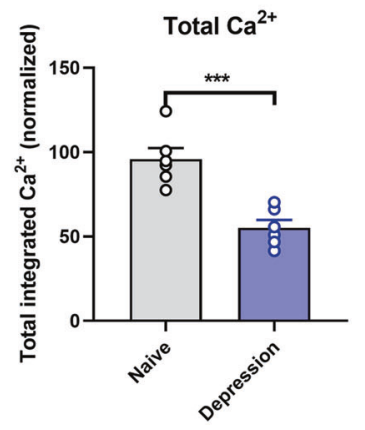

e

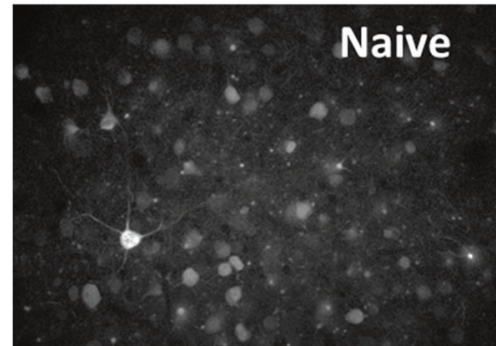

f

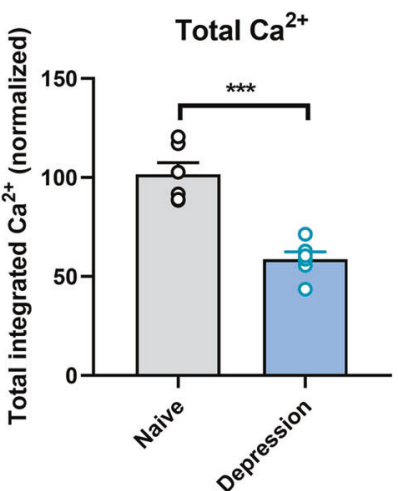

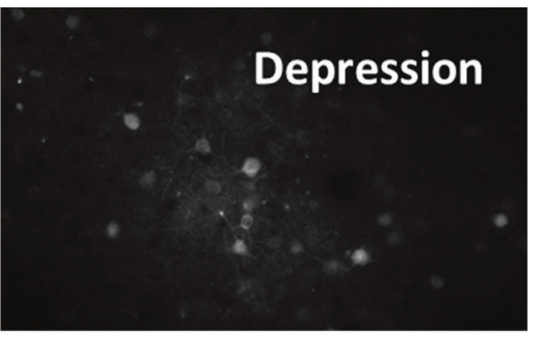

d
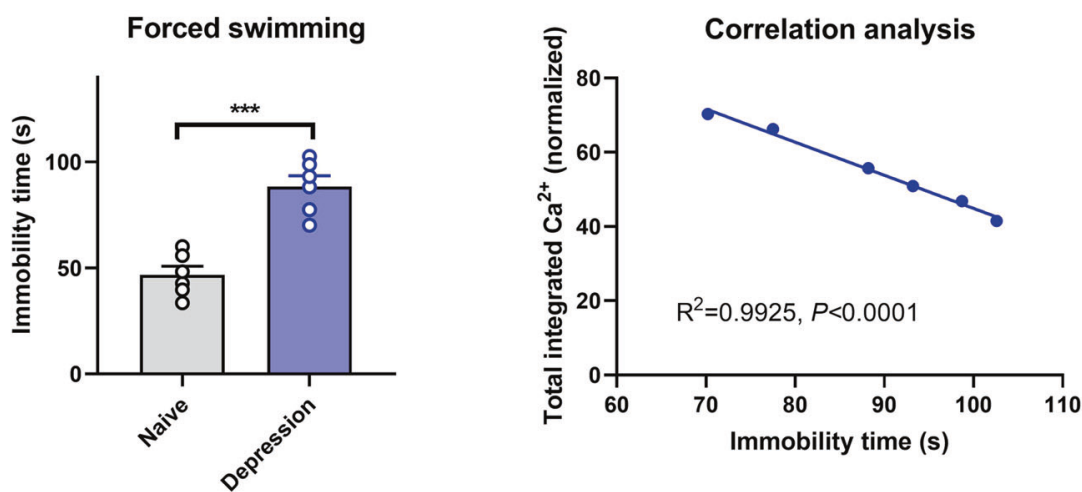

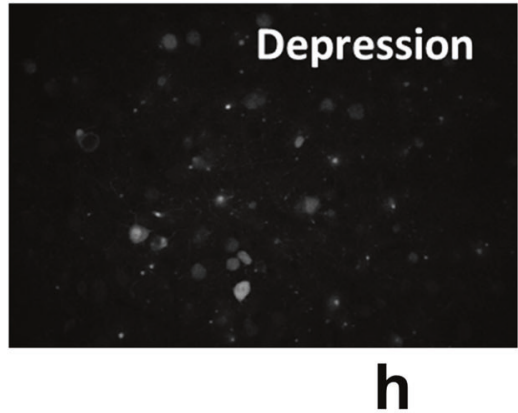

Novel object recognition

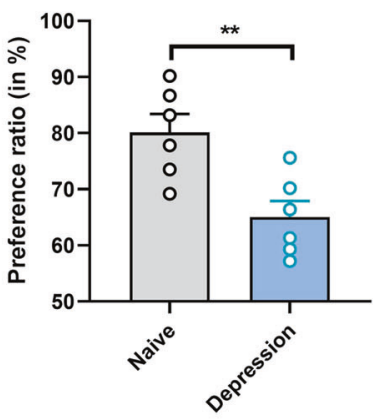

Correlation analysis

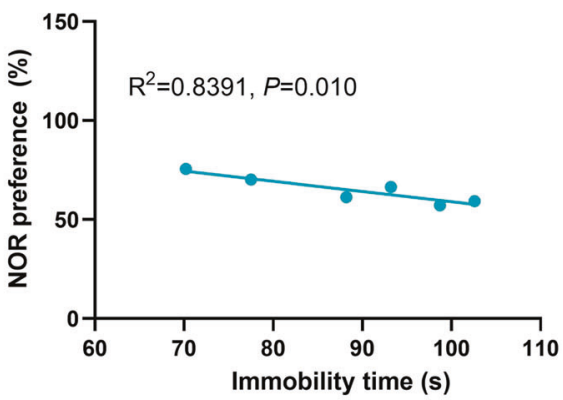

Fig. 1 Brain neural activity and the correlation of Brain neural activity and depressive symptoms in the depressive phase of the murine model of bipolar disorder. a Brain $\mathrm{Ca}^{2+}$ activity in naive murine model; $\mathbf{b}$ Brain $\mathrm{Ca}^{2+}$ activity in the depressive phase in the bipolar disorder murine model; b" Normalized total integrated $\mathrm{Ca}$ in the depressive phase in the bipolar disorder murine model; $\mathbf{c}$ Immobility time in the manci phase in the bipolar disorder murine model; $\mathbf{d}$ The correlation between normalized total integrated $\mathrm{Ca}$ and immobility time in the depressive phase in the bipolar disorder murine model. e Comparison of the Ca between naïve murine model and the depressive phase of bipolar disorder in the depressive phase of the murine model of Bipolar disorder; $\mathbf{f}$ Normalized total integrated Ca in the depressive phase in the bipolar disorder murine model; $\mathbf{g}$ Percentage of preference ratio of the depressive phase in the bipolar disorder murine model; $\mathbf{f}$ Normalized integrated $\mathrm{Ca}$ activity comparison between the naive murine model and depressive phased in the murine model of bipolar disorder; and $\mathbf{h}$ The correlation between normalized total integrated $\mathrm{Ca}$ and immobility time in the depressive phase in the bipolar disorder murine model. 
a
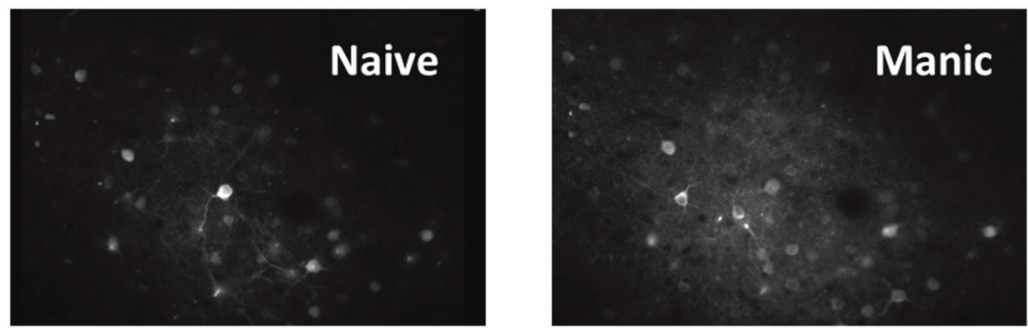

b

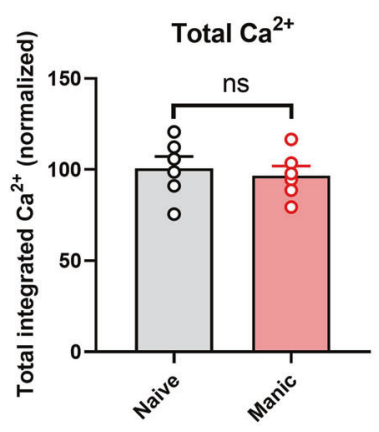

\section{C}

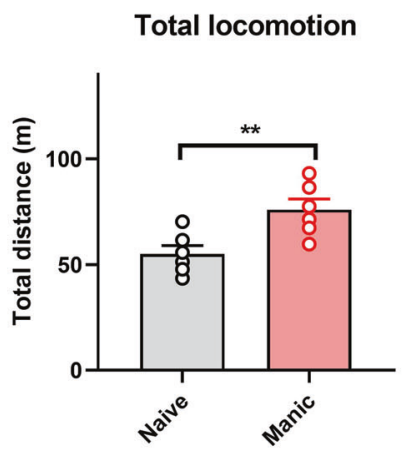

d

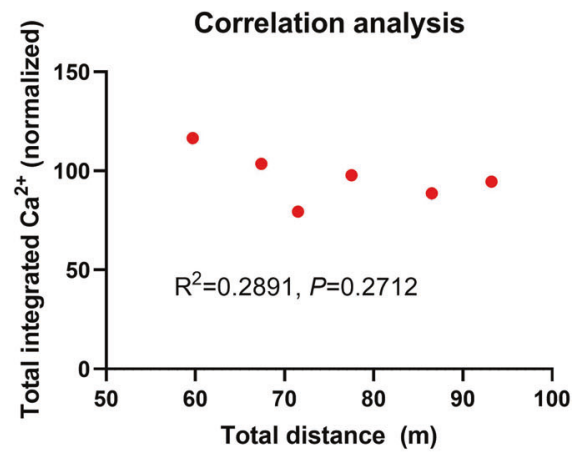

e

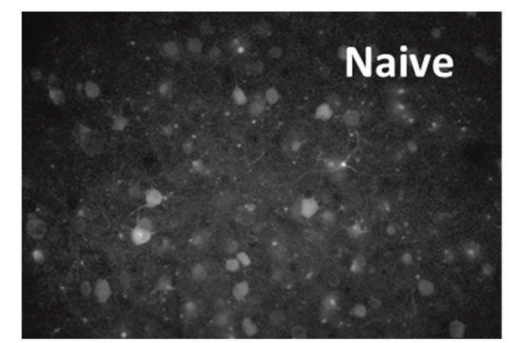

f

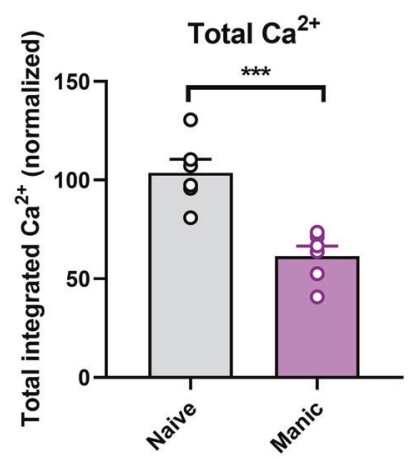

g

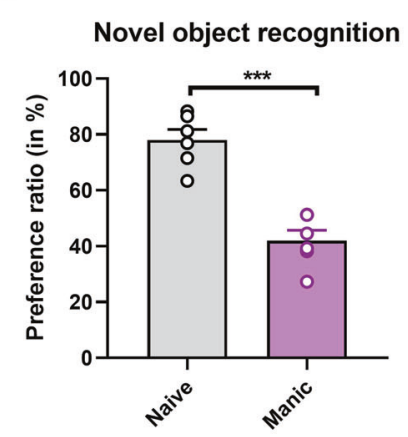

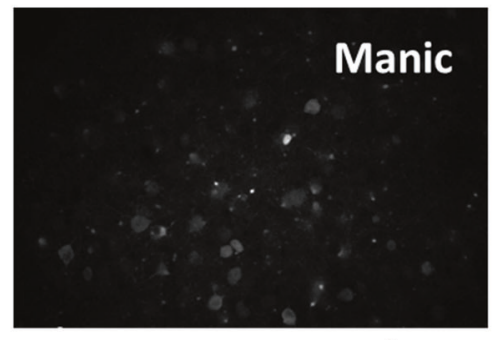

h

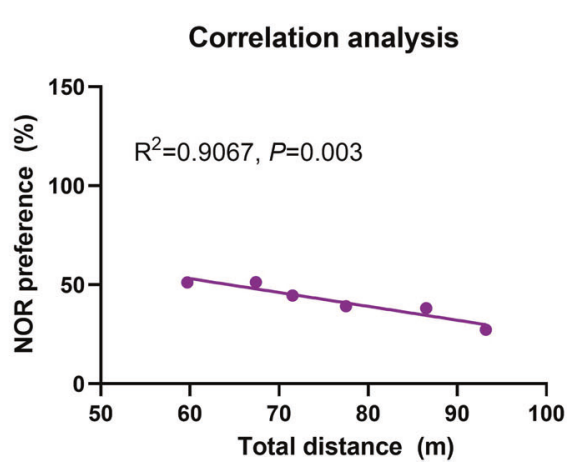

Fig. 2 Brain neural activity and the correlation of Brain neural activity and depressive symptoms in the depressive phase of the murine model of bipolar disorder. a Brain Ca activity in naive murine model; $\mathbf{b}$ Bain Ca activity in the manic phase in the bipolar disorder murine model; b" Normalized total integrated Ca in the manic phase in the bipolar disorder murine model; $\mathbf{c}$ Immobility time in the manci phase in the bipolar disorder murine model; $\mathbf{d}$ The correlation between normalized total integrated $\mathrm{Ca}$ and immobility time in the manic phase in the bipolar disorder murine model. e Comparison of the Ca between naïve murine model and the manic phase of bipolar disorder in the manic phase of the murine model of Bipolar disorder; $\mathbf{f}$ Normalized total integrated $\mathrm{Ca}$ in the manic phase in the bipolar disorder murine model; g Percentage of preference ratio of the manic phase in the bipolar disorder murine model; f Normalized integrated Ca activity comparison between the naive murine model and manic phased in the murine model of bipolar disorder; and $\mathbf{h}$ The correlation between normalized total integrated $\mathrm{Ca}$ and immobility time in the manic phase in the bipolar disorder murine model. 


\section{DISCUSSION}

In this pilot microimaging study conducted with a murine model of BPD, we observed significantly reduced brain $\mathrm{Ca}^{2+}$ activity in the depressive and manic phases, which is consistent with macroimaging findings suggesting that the disruption of the emotional network contributes to mood dysregulation in patients with BPD [20-23]. We also observed cognitive impairment in the depressive and manic phases, which was related to the severity of depressive and manic symptoms. In addition, it was more severe and correlated more strongly with symptom severity in the manic phase. Neural activity impairment did not correlate with manic symptom severity in our BPD model.

Numerous reports, especially those on macro-imaging (functional MRI and EEG) studies, describe decreased brain activity in the TPC in the depressive and manic phases of BPD. For example, Cerullo et al. [82]. reported decreased middle temporal gyrus activation during depressive episodes in patients with BPD and those with unipolar depression. Xiao et al. [83]. reported reduced cortical regional homogeneity (ReHo) in the superior temporal gyrus and increased ReHo in the cerebellum in the manic phase in patients with BPD relative to a euthymic group. The ENIGMA Bipolar Disorder Working Group observed widespread bilateral patterns of reduced cortical thickness in the frontal, temporal, and parietal regions among 6503 adults with BPD [32]. These findings, along with our microimaging findings, indicate a reduced ability to adjust the intrinsic emotional network in animal models of BPD and patients with this disorder.

Our observation that brain $\mathrm{Ca}^{2+}$ activity was related negatively to the severity of depressive, but not manic, symptoms may be related to the pathological mechanism of BPD. Macro-imaging studies have documented clear correlations of symptom severity with brain functional and structural impairment [84-89]. In addition, macro-imaging techniques may not be able to capture brain features in a timely manner during manic or depressive episodes; in other words, a time lag may affect the results. We could not explore this possibility in this study because we did not use EEG or MRI. A few EEG studies have revealed correlations between brain impairment and symptom severity, and a few animal models of BPD have investigated the relationship between depressive or manic symptom severity and brain impairment. Research involving the simultaneous application of multiple technologies is needed to clarify this relationship.

Clinical and macro-imaging studies have shown that cognitive impairment is a pivotal symptom in patients with BPD; similar findings have been obtained with animal models of depression or mania [90-94]. Our finding that cognitive impairment was more severe in the manic phase provides a new clue for investigation of this difficult-to-improve symptom in patients with BPD, although it may have been influenced by confounding factors. We also found that the mice had more difficulty maintaining attention to complete cognitive tasks during the manic phase in this study. This finding is similar to those from macro-imaging studies of patients with BPD [95-99]. A multiple-arm study is needed to clarify this question.

The lack of a relationship between brain activity and behavioral expression in the manic phase in this study may be related to the regional neurological differences observed in murine models of BPD. For example, Hindley et al. [100] reported that GABAergic system-related genes influence neuronal structure and function in the frontostriatal reward system; we did not examine the striatal region in the present study. Moreover, a recent BPD model revealed the involvement of cerebrospinal fluid proteins in neuronal cell-cell and cell-matrix interactions, particularly in the developing brain, and in pathways of importance for lithium's mechanism of action [101]. These findings demonstrate the need for more exploration of the central nervous system processes implicated in BPD, and the relationship between the neurological bases of this disorder and behavioral expression [102].

\section{Limitations}

This study has several limitations. First, our findings may be attributable to our induction of the manic phase immediately after the depressive phase in this study, which most closely models the rapid-cycling or mixed-episode form of BPD [61, 62]. An intervening interval of time may have allowed for brain recovery, avoiding a "double hit" effect of the CUMS and ketamine treatments. However, this dual-modeling approach has not been attempted in previous studies, and experience from clinical practice suggests that most patients with BPD switch phases rapidly; some patients even have mixed manic/depressive episodes. Patients with rapid-cycling or mixed-episode BPD show more serious brain activity and cognitive impairments, with no relationship between the two [91, 103-105]; this evidence seems to support our postulation that our model design caused a floor effect, but multiple-arm studies are needed to clarify this issue. In future research of this type, we will seek to identify a better method for BPD modeling to allow the investigation of neural mechanisms underlying other subtypes of this disorder. Second, we used only a few behavioral and cognitive indices, although these indices are classic for animal models. The development of additional tests for the assessment of cognitive alterations might aid more detailed description of the pathological mechanisms of BPD. Third, with this pilot study we could not gain a precise and full understanding of the neural mechanisms underlying BPD, or identify a potential biomarker for the investigation of this disorder in patients. The brain is a highly sophisticated network related to genes and composed of many sub-networks under dynamic development from infancy to advanced age. Our observation of brain $\mathrm{Ca}^{2+}$ activity after CUMS may partially explain the lack of a relationship between brain functional impairment and behavioral expression in the subsequently induced manic phase. However, we believe that the brain functional impairment caused by CUMS is a feature of the pathological mechanisms underlying BPD. Finally, unknown factors may have influenced the results of this study, given our limited knowledge of the pathological mechanisms of BPD. Further research on the phase-specific brain pathological features of BPD in animal models and patients is needed.

\section{CONCLUSION}

In this study, we investigated the pattern of brain $\mathrm{Ca}^{2+}$ activity impairment, and the relationships of $\mathrm{Ca}^{2+}$ activity and cognitive performance impairment to depressive and manic symptoms and their severity, in a murine model of BPD. The findings are consistent with those of macro-imaging studies of patients with BPD [31-35], implicating intrinsic emotional network disturbance in this disorder and confirming the association of brain neural activity with cognitive impairment during the depressive and manic phases. Brain neural activity correlated with the severity of depressive, but not manic, symptoms in this study. Given the limitations of this pilot study, however, further research is needed to confirm our observations.

\section{REFERENCES}

1. Grande I, Berk M, Birmaher B, Vieta E. Bipolar disorder. Lancet. 2016;387:1561-72.

2. Berk M, Kapczinski F, Andreazza AC, Dean OM, Giorlando F, Maes M, et al. Pathways underlying neuroprogression in bipolar disorder: focus on inflammation, oxidative stress and neurotrophic factors. Neurosci Biobehav Rev. 2011;35:804-17.

3. Berk M. Neuroprogression: pathways to progressive brain changes in bipolar disorder. Int J Neuropsychopharmacol. 2009;12:441-5.

4. Berk M, Berk L, Dodd S, Cotton S, Macneil C, Daglas R, et al. Stage managing bipolar disorder. Bipolar Disord. 2014;16:471-7.

5. Fries GR, Pfaffenseller B, Stertz L, Paz AV, Dargél AA, Kunz M, et al. Staging and neuroprogression in bipolar disorder. Curr Psychiatry Rep. 2012;14:667-75. 
6. Schneider MR, DelBello MP, McNamara RK, Strakowski SM, Adler CM. Neuroprogression in bipolar disorder. Bipolar Disord. 2012;14:356-74.

7. Lyoo IK, Sung YH, Dager SR, Friedman SD, Lee JY, Kim SJ, et al. Regional cerebral cortical thinning in bipolar disorder. Bipolar Disord. 2006;8:65-74.

8. Strakowski SM, DelBello MP, Zimmerman ME, Getz GE, Mills NP, Ret J, et al. Ventricular and periventricular structural volumes in first- versus multipleepisode bipolar disorder. Am J Psychiatry. 2002;159:1841-7.

9. El-Badri SM, Ashton CH, Moore PB, Marsh VR, Ferrier IN. Electrophysiological and cognitive function in young euthymic patients with bipolar affective disorder. Bipolar Disord. 2001;3:79-87.

10. Robinson LJ, Ferrier IN. Evolution of cognitive impairment in bipolar disorder: a systematic review of cross-sectional evidence. Bipolar Disord. 2006;8:103-16.

11. Kato T. Role of mitochondrial DNA in calcium signaling abnormality in bipolar disorder. Cell Calcium. 2008;44:92-102

12. Terrillion CE, Dao DT, Cachope R, Lobo MK, Puche AC, Cheer JF, et al. Reduced levels of Cacna1c attenuate mesolimbic dopamine system function. Genes Brain Behav. 2017;16:495-505.

13. Dao DT, Mahon PB, Cai X, Kovacsics CE, Blackwell RA, Arad M, et al. Mood disorder susceptibility gene CACNA1C modifies mood-related behaviors in mice and interacts with sex to influence behavior in mice and diagnosis in humans. Biol Psychiatry. 2010;68:801-10.

14. Leussis MP, Berry-Scott EM, Saito M, Jhuang H, de Haan G, Alkan O, et al. The ANK3 bipolar disorder gene regulates psychiatric-related behaviors that are modulated by lithium and stress. Biol Psychiatry. 2013;73:683-90.

15. Rueckert EH, Barker D, Ruderfer D, Bergen SE, O'dushlaine C, Luce CJ, et al. Cisacting regulation of brain-specific ANK3 gene expression by a genetic variant associated with bipolar disorder. Mol Psychiatry. 2013;18:922-9.

16. Song JHT, Lowe CB, Kingsley DM. Characterization of a human-specific tandem repeat associated with bipolar disorder and schizophrenia. Am J Hum Genet. 2018;103:421-30.

17. Nelson AD, Caballero-Florán RN, Rodríguez Díaz JC, Hull JM, Yuan Y, Li J, et al. Ankyrin-G regulates forebrain connectivity and network synchronization via interaction with GABARAP. Mol Psychiatry. 2020;25:2800-17.

18. Zhu S, Cordner ZA, Xiong J, Chiu CT, Artola A, Zuo Y, et al. Genetic disruption of ankyrin-G in adult mouse forebrain causes cortical synapse alteration and behavior reminiscent of bipolar disorder. Proc Natl Acad Sci USA. 2017;114:10479-84.

19. Chen J, Müller VI, Dukart J, Hoffstaedter F, Baker JT, Holmes AJ, et al. Intrinsic connectivity patterns of task-defined brain networks allow individual prediction of cognitive symptom dimension of schizophrenia and are linked to molecular architecture. Biol Psychiatry. 2021;1:308-19.

20. Wei SY, Tseng HH, Chang HH, Lu TH, Chang WH, Chiu NT, et al. Dysregulation of oxytocin and dopamine in the corticostriatal circuitry in bipolar II disorder. Transl Psychiatry. 2020;10:281.

21. Fries GR, Li Q, MCAlpin B, Rein T, Walss-Bass C, Soares JC, et al. The role of DNA methylation in the pathophysiology and treatment of bipolar disorder. Neurosci Biobehav Rev. 2016;68:474-88.

22. Burghardt KJ, Goodrich JM, Dolinoy DC, Ellingrod VL. DNA methylation, insulin resistance and second-generation antipsychotics in bipolar disorder. Epigenomics. 2015;7:343-52.

23. Schubeler D. Function and information content of DNA methylation. Nature. 2015;517:321-6.

24. Sayad A, Taheri M, Omrani MD, Fallah H, Oskooei VK, Ghafouri Fard S. Peripheral expression of long non-coding RNAs in bipolar patients. J Affect Disord. 2019;249:169-74.

25. Fries GR, Quevedo J. Exosomal microRNAs as potential biomarkers in neuropsychiatric disorders. Methods Mol Biol. 2018;1733:79-85.

26. Fries GR, Lima CN, Valvassori SS, Zunta-Soares G, Soares JC, Quevedo J. Preliminary investigation of peripheral extracellular vesicles' microRNAs in bipolar disorder. J Affect Disord. 2019;255:10-4.

27. Kempton MJ, Geddes JR, Ettinger U, Williams SC, Grasby PM. Metaanalysis, database, and meta-regression of 98 structural imaging studies in bipolar disorder. Arch Gen Psychiatry. 2008;65:1017-32.

28. Drevets WC, Price JL, Simpson JR JR Jr, Todd RD, Reich T, Vannier M, et al. Subgenual prefrontal cortex bnormalities in mood disorders. Nature. 1997;386:824-7.

29. Ellison-Wright I, Bullmore E. Anatomy of bipolar disorder and schizophrenia: a meta-analysis. Schizophr Res. 2010;117:1-12.

30. Bora E, Fornito A, Yucel M, Pantelis C. Voxelwise meta-analysis of gray matter abnormalities in bipolar disorder. Biol Psychiatry. 2010;67:1097-105.

31. Matsuo K, Harada K, Fujita $Y$, Okamoto $Y$, Ota M, Narita $H$, et al. Distinctive neuroanatomical substrates for depression in bipolar disorder versus major depressive disorder. Cereb Cortex. 2019;29:202-14.

32. Hibar DP, Westlye LT, Doan NT, Jahanshad N, Cheung JW, Ching CRK, et al. Cortical abnormalities in bipolar disorder: an MRI analysis of 6503 individuals from the
ENIGMA Bipolar Disorder Working Group. Mol Psychiatry. 2018;23:932-42. https:// doi.org/10.1038/mp.2017.73.

33. Nortje G, Stein DJ, Radua J, Mataix-Cols D, Horn N. Systematic review and voxelbased meta-analysis of diffusion tensor imaging studies in bipolar disorder. J Affect Disord. 2013;150:192-200.

34. Harrison PJ, Hall N, Mould A, Al-Juffali N, Tunbridge EM. Cellular calcium in bipolar disorder: systematic review and meta-analysis. Mol Psychiatry. 2019. https://doi.org/10.1038/s41380-019-0622-y.

35. Francis MM. Bipolar disorder: a guide for you and your loved ones (A Johns Hopkins Press Health Book). Johns Hopkins University Press; 2020.

36. Hiser J, Koenigs $M$. The multifaceted role of the ventromedial prefrontal cortex in emotion, decision making, social cognition, and psychopathology. Biol Psychiatry. 2018;83:638-47.

37. Zhou Y, Fan L, Qiu C, Jiang T. Prefrontal cortex and the dysconnectivity hypothesis of schizophrenia. Neurosci Bull. 2015;31:207-19.

38. Belleau EL, Treadway MT, Pizzagalli DA. The impact of stress and major depressive disorder on hippocampal and medial prefrontal cortex morphology. Biol Psychiatry. 2019;85:443-53.

39. Sasabayashi D, Takahashi T, Takayanagi Y, Suzuki M. Anomalous brain gyrification patterns in major psychiatric disorders: a systematic review and transdiagnostic integration. Transl Psychiatry. 2021;11:176.

40. Rey G, Bolton TAW, Gaviria J, Piguet C, Preti MG, Favre S, et al. Dynamics of amygdala connectivity in bipolar disorders: a longitudinal study across mood states. Neuropsychopharmacology. 2021;46:1693-701.

41. Nabulsi L, McPhilemy G, O'donoghue S, Cannon DM, Kilmartin L, O'hora D, et al. Aberrant subnetwork and hub dysconnectivity in adult bipolar disorder: a multicenter graph theory analysis. Cereb Cortex. 2021;5:bhab356.

42. Witvliet D, Mulcahy B, Mitchell JK, Meirovitch $Y$, Berger DR, Wu Y, et al. Connectomes across development reveal principles of brain maturation. Nature. 2021;596:257-61.

43. Lu H, Gallinaro JV, Normann C, Rotter S, Yalcin I. Time course of homeostatic structural plasticity in response to optogenetic stimulation in mouse anterior cingulate cortex. Cereb Cortex. 2021;5:bhab281.

44. Legrand A, Iftimovici A, Khayachi A, Chaumette B. Epigenetics in bipolar disorder: a critical review of the literature. Psychiatr Genet. 2021;31:1-12.

45. Gürel Ç, Kuşçu GC, Yavaşoğlu A, Biray Avcı Ç. The clues in solving the mystery of major psychosis: the epigenetic basis of schizophrenia and bipolar disorder. Neurosci Biobehav Rev. 2020;113:51-61.

46. Haggarty SJ, Karmacharya R, Perlis RH. Advances toward precision medicine for bipolar disorder: mechanisms \& molecules. Mol Psychiatry. 2021;26:168-85.

47. Le-Niculescu H, Roseberry K, Gill SS, Levey DF, Phalen PL, Mullen J, et al. Precision medicine for mood disorders: objective assessment, risk prediction, pharmacogenomics, and repurposed drugs. Mol Psychiatry. 2021;26:2776-804.

48. Post RM, Altshuler LL, Kupka R, McElroy SL, Frye MA, Grunze H, et al. 25 years of the International Bipolar Collaborative Network (BCN). Int J Bipolar Disord. 2021;9:13.

49. Manchia M, Vieta E, Smeland OB, Altimus C, Bechdolf A, Bellivier F, et al. European College of Neuropsychopharmacology (ECNP) bipolar disorders network. Translating big data to better treatment in bipolar disorder-a manifesto for coordinated action. Eur Neuropsychopharmacol. 2020;36:121-36.

50. Rotenberg LS, Borges-Júnior RG, Lafer B, Salvini R, Dias RDS. Exploring machine learning to predict depressive relapses of bipolar disorder patients. J Affect Disord. 2021;295:681-87.

51. Lydiard J, Nemeroff CB. Biomarker-guided tailored therapy. Adv Exp Med Biol. 2019;1192:199-224.

52. Hemager N, Plessen KJ, Thorup A, Christiani C, Ellersgaard D, Spang KS, et al. Assessment of neurocognitive functions in 7-year-old children at familial high risk for schizophrenia or bipolar disorder: The Danish High Risk and Resilience Study VIA 7. JAMA Psychiatry. 2018;75:844-52.

53. Cooper A, Horrocks J, Goodday S, Keown-Stoneman C, Duffy A. Predicting the risk and timing of major mood disorder in offspring of bipolar parents: exploring the utility of a neural network approach. Int J Bipolar Disord. 2021;9:22.

54. Roberts G, Lenroot R, Overs B, Fullerton J, Leung V, Ridgway K, et al. Accelerated cortical thinning and volume reduction over time in young people at high genetic risk for bipolar disorder. Psychol Med. 2020;7:1-12. https://doi.org/ $10.1017 /$ S0033291720003153.

55. Meluken I, Ottesen NM, Phan KL, Goldin PR, Di Simplicio M, Macoveanu J, et al. Neural response during emotion regulation in monozygotic twins at high familial risk of affective disorders. Neuroimage Clin. 2019;21:101598.

56. Roberts G, Perry A, Lord A, Frankland A, Leung V, Holmes-Preston E, et al. Structural dysconnectivity of key cognitive and emotional hubs in young people at high genetic risk for bipolar disorder. Mol Psychiatry. 2018;23:413-21.

57. Antoniuk S, Bijata M, Ponimaskin E, Wlodarczyk J. Chronic unpredictable mild stress for modeling depression in rodents: meta-analysis of model reliability. Neurosci Biobehav Rev. 2019;99:101-16. 
58. Bhatt K, Yoo J, Bridges A. Ketamine-induced manic episode. Prim Care Companion CNS Disord. 2021;23:20102811.

59. Banwari G, Desai P, Patidar P. Ketamine-induced affective switch in a patient with treatment-resistant depression. Indian J Pharmacol. 2015;47:454-55.

60. Gao TH, Ni RJ, Liu S, Tian Y, Wei J, Zhao L, et al. Chronic lithium exposure attenuates ketamine-induced mania-like behavior and c-Fos expression in the forebrain of mice. Pharmacol Biochem Behav. 2021;202:173108.

61. Carvalho AF, Dimellis D, Gonda X, Vieta E, Mclntyre RS, Fountoulakis KN. Rapid cycling in bipolar disorder: a systematic review. J Clin Psychiatry. 2014;75: e578-86.

62. Müller JK, Leweke FM. Bipolar disorder: clinical overview. Med Monatsschr Pharm. 2016;39:363-69.

63. Li ES, Saha MS. Optimizing calcium detection methods in animal systems: a sandbox for synthetic biology. Biomolecules. 2021;11:343.

64. Calvo-Rodriguez M, Kharitonova EK, Bacskai BJ. In vivo brain imaging of mitochondrial $\mathrm{Ca}(2+)$ in neurodegenerative diseases with multiphoton microscopy. Biochim Biophys Acta Mol Cell Res. 2021;1868:118998.

65. Zhou C, Kong D, Xue R, Chen M, Li G, Xu Y, et al. Metformin enhances antidepressant/antipsychotic combination therapy of schizophrenia with comorbid depression in a murine model. Front Neurosci. 2020;14:517.

66. Zhou C, Kong D, Zhu X, Wu W, Xue R, Li G, et al. Rethinking schizophrenia and depression comorbidity as one psychiatric disorder entity: evidence from mouse model. Front Neurosci. 2020;14:115.

67. Arslan FC, Tiryaki A, Yıldırım M, Özkorumak E, Alver A, Altun IK, et al. The effects of edaravone in ketamine-induced model of mania in rats. Acta Neurobiol Exp (Wars). 2016;76:192-98.

68. Krug JT, Klein AK, Purvis EM, Ayala K, Mayes MS, Collins L, et al. Effects of chronic lithium exposure in a modified rodent ketamine-induced hyperactivity model of mania. Pharm Biochem Behav. 2019;179:150-55.

69. Machado-Vieira R, Soeiro-De-Souza MG, Richards EM, Teixeira AL, Zarate CA Jr. Multiple levels of impaired neural plasticity and cellular resilience in bipolar disorder: developing treatments using an integrated translational approach. World J Biol Psychiatry. 2014;15:84-95.

70. Ghedim FV, Fraga Dde B, Deroza PF, Oliveira MB, Valvassori SS, Steckert AV, et al. Evaluation of behavioral and neurochemical changes induced by ketamine in rats: implications as an animal model of mania. J Psychiatr Res. 2012;46:1569-75.

71. Ettenberg A, Ayala K, Krug JT, Collins L, Mayes MS, Fisher MPA. Differential effects of lithium isotopes in a ketamine-induced hyperactivity model of mania. Pharm Biochem Behav. 2020;190:172875.

72. Smith GB, Fitzpatrick D. Viral injection and cranial window implantation for in vivo two-photon imaging. Methods Mol Biol. 2016;1474:171-85.

73. Brenowitz SD, Regehr WG. Presynaptic imaging of projection fibers by in vivo injection of dextran-conjugated calcium indicators. Cold Spring Harb Protoc. 2012;2012:465-71.

74. De Giorgio R, Camilleri M. Human enteric neuropathies: morphology and molecular pathology. Neurogastroenterol Motil. 2004;16:515-31.

75. Cooper JE, Natarajan D, McCann CJ, Choudhury S, Godwin H, Burns AJ, et al. In vivo transplantation of fetal human gut-derived enteric neural crest cells. Neurogastroenterol Motil. 2017;29:e12900.

76. Feldcamp LA, Boutros PC, Raymond R, Fletcher PJ, Nobrega JN, Wong AHC. Pdxdc1 modulates prepulse inhibition of acoustic startle in the mouse. Transl Psychiatry. 2017;7:e1125.

77. Frau R, Abbiati F, Bini V, Casti A, Caruso D, Devoto P, et al. Targeting neurosteroid synthesis as a therapy for schizophrenia-related alterations induced by early psychosocial stress. Schizophr Res. 2015;168:640-48.

78. Kaygisiz B, Aydin S, Yildirim E, Musmul A, Erol K, Kilic FS. The effects of galangin in prepulse inhibition test and experimental schizophrenia models. Acta Neuropsychiatr. 2021;20:1-27.

79. Wake N, Ishizu K, Abe T, Takahashi H. Prepulse inhibition predicts subjective hearing in rats. Sci Rep. 2021;11:18902.

80. Valls-Sole J. Prepulse inhibition on the spot. Clin Neurophysiol. 2021;132:2679-80.

81. Du W, Li M, Zhou H, Shao F, Wang W. Alteration of the PKA-CREB cascade in the mPFC accompanying prepulse inhibition deficits: evidence from adolescent social isolation and chronic SKF38393 injection during early adolescence. Behav Pharmacol. 2021;32:487-96.

82. Cerullo MA, Eliassen JC, Smith CT, Fleck DE, Nelson EB, Strawn JR, et al. Bipolar I disorder and major depressive disorder show similar brain activation during depression. Bipolar Disord. 2014;16:703-12.

83. Xiao Q, Cui D, Jiao Q, Zhong Y, Cao W, Lu G, et al. Altered regional homogeneity in bipolar disorder during manic and euthymic state: a resting-state fMRI study. Brain Imaging Behav. 2019;13:1789-98.

84. Gong J, Wang J, Chen P, Qi Z, Luo Z, Wang J, et al. Large-scale network abnormality in bipolar disorder: a multimodal meta-analysis of resting-state functional and structural magnetic resonance imaging studies. J Affect Disord. 2021;292:9-20.
85. Cahn AJ, Keramatian K, Frysch C, Yatham LN, Chakrabarty T. Longitudinal grey matter changes following first episode mania in bipolar I disorder: a systematic review. J Affect Disord. 2021;291:198-208.

86. Angelescu I, Brugger SP, Borgan F, Kaar SJ, Howes OD. The magnitude and variability of brain structural alterations in bipolar disorder: a double meta-analysis of 5534 patients and 6651 healthy controls. J Affect Disord. 2021;291:171-76.

87. Gong J, Wang J, Qiu S, Chen P, Luo Z, Wang J, et al. Common and distinct patterns of intrinsic brain activity alterations in major depression and bipolar disorder: voxel-based meta-analysis. Transl Psychiatry. 2020;10:353.

88. Keramatian K, Chakrabarty T, Saraf G, Pinto JV, Yatham LN. Grey matter abnormalities in first-episode mania: a systematic review and meta-analysis of voxel-based morphometry studies. Bipolar Disord. 2021;23:228-40.

89. Vai B, Bertocchi C, Benedetti F. Cortico-limbic connectivity as a possible biomarker for bipolar disorder: where are we now? Expert Rev Neurother. 2019;19:159-72.

90. Fountoulakis KN. Neurocognitive impairment and evidence-based treatment options in bipolar disorder. Ann Gen Psychiatry. 2020;19:54.

91. Van Rheenen TE, Lewandowski KE, Bauer IE, Kapczinski F, Miskowiak K, Burdick $\mathrm{KE}$, et al. Current understandings of the trajectory and emerging correlates of cognitive impairment in bipolar disorder: an overview of evidence. Bipolar Disord. 2020;22:13-27.

92. Bora E. Neurocognitive features in clinical subgroups of bipolar disorder: a metaanalysis. J Affect Disord. 2018;229:125-34.

93. Solé $B$, Jiménez $E$, Torrent $C$, Reinares $M$, Bonnin CDM, Torres I, et al. Cognitive impairment in bipolar disorder: treatment and prevention strategies. Int $J$ Neuropsychopharmacol. 2017;20:670-80.

94. Cardenas SA, Kassem L, Brotman MA, Leibenluft E, McMahon FJ. Neurocognitive functioning in euthymic patients with bipolar disorder and unaffected relatives: a review of the literature. Neurosci Biobehav Rev. 2016;69:193-215.

95. Kuang L, Gao W, Wang L, Guo Y, Cao W, Cui D, et al. Increased resting-state brain entropy of parahippocampal gyrus and dorsolateral prefrontal cortex in manic and euthymic adolescent bipolar disorder. J Psychiatr Res. 2021;143:106-12.

96. Lomastro MJ, Valerio MP, Szmulewicz AG, Martino DJ. Manic morbidity and executive function impairment as determinants of long-term psychosocial dysfunction in bipolar disorder. Acta Psychiatr Scand. 2021;144:72-81.

97. Sarmento SMS, Bittencourt L, de Mendonça Filho EJ, Abreu N, Tavares de Lacerda AL, Miranda-Scippa Â. Neurocognitive impairment in bipolar disorder and associated factors: using population-based norms and a strict criterion for impairment definition. Cogn Behav Neurol. 2020;33:103-12.

98. Young JW, Geyer MA, Halberstadt AL, van Enkhuizen J, Minassian A, Khan A, et al. Convergent neural substrates of inattention in bipolar disorder patients and dopamine transporter-deficient mice using the 5-choice CPT. Bipolar Disord. 2020;22:46-58.

99. Fries GR, Valvassori SS, Bock H, Stertz L, Magalhães PV, Mariot E, et al. Memory and brain-derived neurotrophic factor after subchronic or chronic amphetamine treatment in an animal model of mania. J Psychiatr Res. 2015;68:329-36.

100. Hindley G, Bahrami S, Steen NE. Characterising the shared genetic determinants of bipolar disorder, schizophrenia and risk-taking. Transl Psychiatry. 2021;11:466.

101. Zhang R, Song J, Isgren A, Jakobsson J, Blennow K, Sellgren CM, Zetterberg H, Bergen SE, Landén M. Genome wide study of immune biomarkers in cerebrospinal fluid and serum from patients with bipolar disorder and controls. Transl Psychiatry. 2020;10:58. https://doi.org/10.1038/s41398-020-0737-6.

102. Serafini G, Pardini M, Monacelli F, Orso B, Girtler N, Brugnolo A, et al. Neuroprogression as an illness trajectory in bipolar disorder: a selective review of the current literature. Brain Sci. 2021;11:276.

103. Sidor MM, Spencer SM, Dzirasa K, Parekh PK, Tye KM, Warden MR, et al. Daytime spikes in dopaminergic activity drive rapid mood-cycling in mice. Mol Psychiatry. 2015;20:1406-19.

104. Mastwal S, Ye Y, Ren M, Jimenez DV, Martinowich K, Gerfen CR, et al. Phasic dopamine neuron activity elicits unique mesofrontal plasticity in adolescence. J Neurosci. 2014;16:9484-96.

105. Leibenluft E, Charney DS, Pine DS. Researching the pathophysiology of pediatric bipolar disorder. Biol Psychiatry. 2003;53:1009-20.

\section{AUTHOR CONTRIBUTIONS}

$\mathrm{CHZ}, \mathrm{CZ}, \mathrm{YX}$, and $\mathrm{HT}$ conceived and designed the research. DGC, CC, Chuanxin Liu, $M C, F Z, J Z, D J, X L, T F, L C$, and MC collected the data and conducted the research. Guoyong Huang, GL, Guoyong Huang, JS, ZC, HT, and $\mathrm{CHZ}$ analyzed and interpreted the data. Guangchuan Huang, CL, CZ, and HT wrote the initial manuscript. GL and SC revised the manuscript. Guangchuan Huang, Chongguang Lin, MC, and CZ had primary responsibility for the final manuscript content. All authors read and approved the final manuscript. 


\section{FUNDING}

This work was supported by grants from the National Natural Science Foundation of China (81871052, 82171503 to CZ); the Key Projects of the Natural Science Foundation of Tianjin, China (17JCZDJC35700 to CZ); the Tianjin Health Bureau Foundation (2014KR02 to CZ); and the Tianjin Science and Technology Bureau (15JCYBJC50800 to HT).

\section{COMPETING INTERESTS}

The authors declare no competing interests.

\section{ADDITIONAL INFORMATION}

Correspondence and requests for materials should be addressed to Min Chen, Chongguang Lin or Chuanjun Zhuo.

Reprints and permission information is available at http://www.nature.com/ reprints
Publisher's note Springer Nature remains neutral with regard to jurisdictional claims in published maps and institutional affiliations.

cc) (1)

Open Access This article is licensed under a Creative Commons Attribution 4.0 International License, which permits use, sharing, adaptation, distribution and reproduction in any medium or format, as long as you give appropriate credit to the original author(s) and the source, provide a link to the Creative Commons license, and indicate if changes were made. The images or other third party material in this article are included in the article's Creative Commons license, unless indicated otherwise in a credit line to the material. If material is not included in the article's Creative Commons license and your intended use is not permitted by statutory regulation or exceeds the permitted use, you will need to obtain permission directly from the copyright holder. To view a copy of this license, visit http://creativecommons. org/licenses/by/4.0/.

(c) The Author(s) 2021 